\title{
'Dialysis related arthropathy': a survey of 95 patients receiving chronic haemodialysis with special reference to $\beta_{2}$ microglobulin related amyloidosis
}

\author{
N P HURST ${ }_{1}^{1}$ R VAN DEN BERG ${ }_{1}^{1}$ A DISNEY,$^{2}$ M ALCOCK ${ }^{3}$ L ALBERTYN ${ }^{3}$ \\ $M$ GREEN, ${ }^{\prime}$ AND V PASCOE \\ From the ${ }^{1}$ Rheumatology Unit, the ${ }^{2}$ Renal Unit, the ${ }^{3}$ Department of Radiology, and the ${ }^{4}$ Department of \\ Pathology, The Queen Elizabeth Hospital, Woodville, South Australia
}

SUMMARY Ninety five patients receiving chronic haemodialysis (CHD) were surveyed to determine the prevalence of rheumatic disease and, where possible, its aetiology. At least three distinct rheumatic syndromes were identified-a group of patients with a syndrome consisting of large and medium joint synovial swelling, restricted hips and shoulders, tenosynovitis, carpal tunnel syndrome, and bone cysts due to deposition of $\beta_{2}$ microglobulin related amyloid $\left(\mathrm{AM}_{\beta 2 \mathrm{~m}}\right)$; a second group with erosive azotaemic osteoarthropathy; and a third group with age related degenerative disease of small, large, and axial joints. The data presented suggest that in patients receiving CHD (a) the prevalence of $\mathrm{AM}_{\beta 2 \mathrm{~m}}$ deposition and the associated syndrome increases with duration of dialysis, but in patients who have been dialysed for more than 10 years the risk of developing $\mathrm{AM}_{\beta 2 \mathrm{~m}}$ is related to age; (b) $\mathrm{AM}_{\beta 2 \mathrm{~m}}$ deposition in subchondral cysts, but not synovium, causes joint destruction; also, $\mathrm{AM}_{\beta 2 \mathrm{~m}}$ may be more prone to deposition in synovium of joints already damaged by other processes; $(c)$ in the absence of synovial iron deposition synovial $\mathrm{AM}_{\beta 2 \mathrm{~m}}$ is not associated with an inflammatory infiltrate; $(d)$ hyperparathyroidism and perhaps other factors such as synovial iron deposition are probably more important than $\mathbf{A M}_{\beta 2 \mathrm{~m}}$ as causes of peripheral joint degeneration and destructive spondyloarthropathy in patients receiving CHD.

A number of skeletal and articular abnormalities have been described in patients undergoing chronic haemodialysis (CHD). These include renal osteodystrophy, avascular necrosis of bone, crystal induced arthritis, periarticular calcification, ${ }^{1-3}$ and recurrent haemarthrosis of shoulders. ${ }^{2}{ }^{3}$ A syndrome, comprising carpal tunnel syndrome (CTS), ${ }^{3-8}$ chronic large joint arthropathy, ${ }^{39}$ and bone cysts, ${ }^{10}$ has also been recognised as a major complication of CHD. Recent studies have demonstrated the deposition of amyloid in the carpal tunnel, bone cysts, synovium, and tendons of such patients. ${ }^{810-14}$ The major component of the amyloid has been identified as $\beta_{2}$ microglobulin, ${ }^{15-23}$ but amyloid $\mathrm{P}$ component is also present. ${ }^{21} \mathrm{~A}$ suggested designation is ' $A M_{\beta 2 m}$ ' ${ }^{19}{ }^{A 4} M_{\beta 2 m}$ has also been identified in synovial fluid ${ }^{24}$ and vertebral discs. ${ }^{25}$ $\mathrm{AM}_{\beta 2 \mathrm{~m}}$ deposits have been infrequently described in other major organs ${ }^{12} 23$ and, where present, are

Accepted for publication 27 July 1988.

Correspondence to Dr N P Hurst, Rheumatology Unit. The Queen

Elizabeth Hospital, Woodville, South Australia 5011. usually small and perivascular. ${ }^{26} 27 \mathrm{~A}$ similar tropism for synovial tissue has been described previously for AL-type amyloid, ${ }^{28}$ but AA-type amyloid usually spares synovium and bone. A minor degree of synovial amyloidosis occurs with increasing age. ${ }^{29}$

Some bone deposits of $\mathrm{AM}_{\beta 2 \mathrm{~m}}$ have been responsible for fractures, ${ }^{30} 31$ and it has been suggested that $\mathrm{AM}_{\beta 2 \mathrm{~m}}$ is responsible for the erosive arthropathy ${ }^{11} 132123$ and spondyloarthropathy ${ }^{25}$ which may occur in patients undergoing CHD. It is not certain, however, whether amyloid alone or other factors such as synovial iron deposition contribute to the large and medium joint arthropathy associated with this syndrome. ${ }^{3} 32$

The present study was undertaken to assess the prevalence of rheumatic disease and, where possible, its relation with tissue deposition of $\mathrm{AM}_{\beta 2 \mathrm{~m}}$ or other factors in a defined population of patients receiving CHD.

\section{Patients and methods}

The patient population consisted of all 118 patients 
receiving $\mathrm{CHD}$ under the care of the Queen Elizabeth Hospital renal unit during a defined nine month period (May 1986-January 1987). Of these, 23 patients were excluded from the study: seven had received renal transplants, two died before being reviewed, and a further 14 patients who were dialysed at remote regional centres ( $>250$ miles) were not seen for logistic reasons. Ninety five patients (40 female, 55 male) were available for review.

All patients were reviewed for symptoms of musculoskeletal disease or symptoms related to systemic amyloidosis using a structured questionnaire and then underwent a complete physical examination performed by one of two rheumatologists ( $\mathrm{NH}, \mathrm{R}$ van den $\mathrm{B})$. The presence of joint 'restriction' was defined as loss of $30 \%$ or more of the normal range of movement and 'synovitis' as the presence of palpable synovial thickening or clinically detectable effusion, or both. CTS was or had been diagnosed on the basis of a typical clinical history, physical findings, and nerve conduction studies. In all cases details of dialysis, cause of renal failure, and parathyroid status were obtained by review of case records.

All patients had radiographs taken of hands, wrists, shoulders, hips, knees, feet, and spine. These were reviewed by two radiologists (LA, MA) experienced in reporting renal bone disease. A radiological diagnosis of renal osteodystrophy was made if any of the following were present: subperiosteal resorption, tuft resorption, distal clavicular erosions, rugger jersey spine or other typical bony sclerosis, or coarse bony trabeculation. A diagnosis of significant active hyperparathyroidism was based on finding either (a) typical radiological changes and parathyroid hormone $>1000 \mathrm{pmol} / \mathrm{l}$ or (b) a bone biopsy specimen showing active bone resorption. Nodal erosive osteoarthrosis of hands was defined as loss of joint space, osteophyte formation, and erosive bone damage, usually affecting interphalangeal or first carpometacarpal joints. Erosive azotaemic osteoarthropathy was defined as the presence of marginal joint erosions, usually affecting metacarpophalangeal or interphalangeal joints, and occasionally larger joints, in the absence of joint space narrowing.

The following biochemical studies were performed on serum or plasma from all patients: serum $\beta_{2}$ microglobulin before and after dialysis, $C$ reactive protein, ferritin, serum electrophoresis, rheumatoid factor, and antinuclear factor. Parathyroid hormone was measured by immunoassay for the $\mathrm{C}$ terminal fragment.

Iliac crest bone biopsy results were reviewed from $68 / 95$ patients. All biopsies had been carried out within 18 months of the study and most within 12 ? months. The remaining patients had either declined $\underset{\overrightarrow{0}}{\overrightarrow{0}}$ to undergo bone biopsy or the available biopsy had $\stackrel{\text { ? }}{\circ}$ been performed more than 18 months previously. Other histological specimens were available from $12 \frac{\overline{\bar{c}}}{\bar{n}}$ patients and synovial fluid from a further seven $\vec{\sigma}_{\bar{\sigma}}$ patients. These were examined for the presence of $\varrho$ amyloid by Congo red staining. Where Congophiliaw was identified the presence of $\beta_{2}$ microglobulin was $\vec{\circ}$ sought using rabbit antihuman $\beta_{2}$ microglobulin antibody and the peroxidase-antiperoxidase tech- $\vec{\omega}$ nique (Dakopatt). Tissues containing either AA or AL-type amyloid were used as negative controls for immunoperoxidase studies. Deposition of iron in $\stackrel{p}{\infty}$ tissues was sought using Perls' stain. Synovial fluider was centrifuged and the sediment examined for the $\vec{p}$ presence of crystals by polarising microscopy, or deposits of $\mathrm{AM}_{\beta 2 \mathrm{~m}}$ using the immunoperoxidase technique followed by Congo red. ${ }^{24}$

\section{Results}

PATIENTS

Patients were divided into three cohorts according to duration of haemodialysis: group $A=0$ to 4.9 옹 years $(n=49)$, group $B=5$ to 9.9 years $(n=32)$, and group $C \geqslant 10$ years $(n=14)$. The mean (SD) ages were: group A $55.8(11.9)$, group B $46.8(13.3), \stackrel{\square}{\complement}$ group C $52 \cdot 1(13 \cdot 2)$ years.

The causes of renal failure included AA-type $\frac{O}{3}$ amyloid in one patient and multiple myeloma in another. They had received dialysis for two yearso and one year respectively and neither had arthropathy, bone cysts, or CTS.

Patients had been treated mostly with cuprophane membrane dialysers. Reverse osmosis has been used? for the last 10 years ensuring dialysate aluminiumo concentrations $<10 \mu \mathrm{mol} / \mathrm{l}$.

CLINICAL AND RADIOLOGICAL FINDINGS

Joint symptoms

Pain and stiffness affecting peripheral and axial $\stackrel{N}{\sim}$ joints were very common and the frequency rose $N$ with increasing duration of dialysis (Table 1).

\section{Large and medium size joints}

The frequency of joint restriction, synovitis, and effusions in large and medium size joints rose with ${ }^{\stackrel{?}{+}}$ duration of dialysis and affected over $60 \%$ of the patients in group $C$ (Tables 1 and 2).

Synovitis was most common in the knee (Table 2$) ; \stackrel{\mathbb{\otimes}}{\stackrel{\mathbb{P}}{\mathbb{Q}}}$ in five of these patients there was no radiological ${ }_{\Omega}^{\mathbb{D}}$ change, in five osteoarthritis, in one a large subchondral tibial cyst later shown to contain $\mathrm{AM}_{\beta 2 \mathrm{~m}} \varnothing$ (see below), and in one loss of articular cartilage. In? 
one patient with an acute painless effusion haemarthrosis was found but no organisms or crystals. Restriction of knee movements was an infrequent finding (Table 2).

Chronic synovitis of shoulders was less common than restriction (Table 2), and these signs occurred together in two patients. In two patients with acute painful exacerbation of chronic synovitis haemarthrosis was found; from one of these Escherichia coli was isolated but in the other no explanation was

Table 1 Clinical abnormalities. The number (\%) of patients affected in each cohort ${ }^{*}$ is shown

\begin{tabular}{|c|c|c|c|c|}
\hline & $\begin{array}{l}A \\
(n=49)\end{array}$ & $\begin{array}{l}B \\
(n=32)\end{array}$ & $\begin{array}{l}C \\
(n=14)\end{array}$ & $p$ Valuet \\
\hline \multicolumn{5}{|l|}{ Large/medium joints } \\
\hline Pain/stiffness & $14(29)$ & $12(38)$ & $11(79)$ & $<0.001$ \\
\hline Synovitis/effusion & $2(4)$ & $5(16)$ & $8(57)$ & $<0.001$ \\
\hline Restriction & $11(22)$ & $12(38)$ & $9(64)$ & $<0 \cdot 01$ \\
\hline \multicolumn{5}{|l|}{ Small joints (hands) } \\
\hline Pain/stiffness & $26(53)$ & $20(63)$ & $13(93)$ & $<0.01$ \\
\hline Synovitis/effusion & $0(0)$ & $1(3)$ & $1(7)$ & NS \\
\hline Osteoarthritis & $12(24)$ & $4(13)$ & $3(21)$ & NS \\
\hline Flexor tenosynovitis & $1(2)$ & $0(0)$ & $3(21)$ & $<0.01$ \\
\hline \multicolumn{5}{|l|}{ Axial joints } \\
\hline Pain/stiffness & $13(27)$ & $12(38)$ & $6(43)$ & NS \\
\hline Restriction & $6(12)$ & $6(19)$ & $4(29)$ & \\
\hline Carpal tunnel syndrome & $0(0)$ & $1(3)$ & $6(43)$ & $<0.001$ \\
\hline \multicolumn{5}{|c|}{$\begin{array}{l}{ }^{*} \text { Duration of dialysis for each group was as follows: } A=0-4.9 \\
\text { years; } B=5-9.9 \text { years; } C=\geqslant 10 \text { years. } \\
+\chi^{2} \text { test, group } C \vee \text { group } A \text {. }\end{array}$} \\
\hline \multicolumn{5}{|c|}{$\begin{array}{l}\text { Table } 2 \text { Distribution of synovitis and restriction in } \\
\text { peripheral joints (number of patients affected) }\end{array}$} \\
\hline Joint & Syno & ovitis & & Restriction \\
\hline Knees & 12 & & & 4 \\
\hline Shoulders & 3 & & & 14 \\
\hline Elbows & 1 & & & 6 \\
\hline Wrists & 1 & & & 5 \\
\hline Hips & - & & & 17 \\
\hline Subtalars & - & & & 6 \\
\hline \multicolumn{5}{|l|}{ Total number of affected } \\
\hline
\end{tabular}

found for bleeding. Several patients had radiological evidence of major rotator cuff attrition, often associated with loss of articular cartilage and secondary osteoarthritis, but only one had synovitis. The frequency of significant rotator cuff disease increased with age (Table 3 ) but not with duration of dialysis (Table 4).

Restriction of hip movement was seen in 17 patients. This was associated with no radiological abnormality in 10 , femoral head cysts in two, osteoarthritis in three and avascular necrosis with secondary osteoarthritis in three patients, of whom two had required total hip replacement. Asymptomatic femoral neck cysts or avascular necrosis respectively were seen in two and three patients each. Thus no radiological abnormality was identi-

Table 4 Number (\%) of patients with radiological abnormalities, analysed by cohorts*

\begin{tabular}{|c|c|c|c|c|}
\hline Abnormality & $\begin{array}{l}A \\
(n=49)\end{array}$ & $\begin{array}{l}B \\
(n=32)\end{array}$ & $\begin{array}{l}C \\
(n=14)\end{array}$ & $p$ Valuet \\
\hline \multicolumn{5}{|l|}{ Bone cysts } \\
\hline In any site & $5(10)$ & $9(28)$ & $7(50)$ & $<0.001$ \\
\hline In carpi & $4(8)$ & $7(22)$ & $4(29)$ & $<0.05$ \\
\hline Renal osteodystrophy & $12(24)$ & $9(28)$ & $9(64)$ & $<0.001$ \\
\hline $\begin{array}{l}\text { Erosive azotaemic } \\
\text { osteoarthropathy }\end{array}$ & $6(12)$ & $4(13)$ & $4(29)$ & NS \\
\hline \multicolumn{5}{|l|}{ Small joints of hands } \\
\hline OAf-total & $15(31)$ & $12(38)$ & $4(29)$ & NS \\
\hline OA-erosive & 7 (14) & 6 (19) & $1(7)$ & NS \\
\hline OA-non-erosive & $8(16)$ & $6(19)$ & $3(21)$ & NS \\
\hline \multicolumn{5}{|l|}{ Large/medium joints } \\
\hline OA (excludes AVN $\ddagger$ ) & 13 (27) & $7(22)$ & $5(36)$ & NS \\
\hline $\begin{array}{l}\text { AVN } \\
\text { Cartilage erosion }\end{array}$ & $1(2)$ & $5(16)$ & $0(0)$ & NS \\
\hline without OA & $5(10)$ & $0(0)$ & $1(7)$ & NS \\
\hline \multicolumn{5}{|l|}{ Axial joints } \\
\hline $\begin{array}{l}\text { apophyseal joint } \mathrm{OA} \\
\text { Rotator cuff disease }\end{array}$ & $3(6)$ & $3(9)$ & $4(29)$ & $<0.02$ \\
\hline Major & $5(10)$ & $3(9)$ & $1(7)$ & NS \\
\hline Minor & $4(8)$ & $5(16)$ & $2(14)$ & NS \\
\hline
\end{tabular}

${ }^{*}$ Duration of dialysis for each group was as follows: $A=0-4.9$ years; $B=5-9.9$ years; $C=\geqslant 10$ years.

$+\chi^{2}$ test, group $C v$ group $A$.

$\ddagger \mathrm{OA}=$ osteoarthritis; $\mathrm{AVN}=$ avascular necrosis.

§Major=upward subluxation of humeral head; minor=rotator cuff calcification or sclerosis of greater tuberosity.

Table 3 Relation between radiological changes of osteoarthritis and age. The number (\%) of patients affected is shown

\begin{tabular}{llllll}
\hline Age (years) & Number & $\begin{array}{l}\text { Large } \\
\text { joint } \text { OA }^{*}\end{array}$ & $\begin{array}{l}\text { Cartilage erosion } \\
\text { without OA }\end{array}$ & $\begin{array}{l}\text { Erosive } \\
\text { nodal OA }\end{array}$ & $\begin{array}{l}\text { Major rotator } \\
\text { cuff disease }\end{array}$ \\
\hline $20-39$ & 24 & $1(4)$ & $0(0)$ & $2(8)$ & 0 \\
$40-59$ & 39 & $12(31)$ & $2(5)$ & $5(13)$ & $2(5)$ \\
$60-79$ & 32 & $10(31)$ & $4(13)$ & $7(22)$ & $7(22)$ \\
\hline
\end{tabular}

*OA=osteoarthritis. 
fied in over half of the patients $(59 \%)$ with hip restriction.

The prevalence of large and medium joint osteoarthritis (excluding cases of avascular necrosis), or loss of articular cartilage without osteoarthritis, increased with age (Table 3 ) but not duration of dialysis (Table 4). Two of the six patients with avascular necrosis had not received corticosteroids.

\section{Small joints}

Small joint symptoms were frequent and increased with duration of dialysis (Table 1). Symptoms were associated with osteoarthritis in 31 patients, erosive azotaemic osteoarthropathy in six patients, metacarpophalangeal joint synovitis in two, and flexor tenosynovitis in four, but no cause was identified in 16.

In those with erosive osteoarthritis pain, instability, and deformity of the interphalangeal or first carpometacarpal joints often caused significant functional disability. Restriction of finger movements was not usually a significant functional problem except in those with flexor tenosynovitis (see below). The frequency of objective clinical or radiological signs of osteoarthritis increased with age but not with increasing duration of dialysis (Tables 1, 3, and 4). Two patients had developed erosive osteoarthritis at a young age (less than 30 years), suggesting that factors associated with renal failure had contributed. Neither had any occupational or other physical risk factor which might have contributed.

Fourteen patients had erosive azotaemic osteoarthropathy, of whom two also had osteoarthritis. In patients with erosive azotaemic osteoarthropathy small erosions were seen adjacent to the metacarpophalangeal and proximal interphalangeal joints, but in two cases were also noted adjacent to the tibial plateau and glenoid fossa respectively. Only six patients with erosive azotaemic osteoarthropathy had small joint symptoms. There was no significant correlation either between the presence of osteoarthritis and erosive azotaemic osteoarthropathy $\left(\chi^{2}\right.$ test; $p>0.5$ ) or between small joint symptoms and erosive azotaemic osteoarthropathy $\left(\chi^{2}\right.$ test; $p>0 \cdot 5)$. The possible relation between erosive azotaemic osteoarthropathy and renal osteodystrophy is discussed below.

A further two patients with small joint symptoms had metacarpophalangeal joint synovitis, of whom one had ulnar deviation. Both had negative tests for rheumatoid factor and antinuclear factor and normal plasma protein electrophoresis, but one had erosive azotaemic osteoarthropathy. A further four patients had flexor tenosynovitis of the fingers associated with marked tendon crepitus and im- paired finger flexion (Table 1). In two of these four 음. patients the appearances resembled diabetic cheir $\stackrel{-}{\Rightarrow}$ arthropathy, and both also had chronic large joint $\stackrel{\vec{f}}{\rightarrow}$ synovitis. Neither patient was diabetic.

Axial joints

Restriction of spinal movement was found in $16 \stackrel{\mathbb{\Phi}}{\mathbb{2}}$ patients and was often sufficiently severe as to suggest the possibility of ankylosing spondylitis. The $\vec{A}$ frequency of symptoms and signs rose with duration. of dialysis. In six patients the stiffness affected the $\vec{\omega}$ whole spine, in five it affected the cervical spine $\stackrel{S}{\circ}$ alone, in three the thoracolumbar spine, and in two $\frac{0}{2}$ the lumbar spine alone. In one of these patients lumbar disc protrusion and, subsequently, synovialo cysts arising from lumbar apophyseal joints caused ${ }_{f}$ lumbar root compression requiring operative in- 8 tervention. The synovium of these joints, and to a을 lesser extent the degenerating disc, was found to be densely infiltrated with $\mathrm{AM}_{\beta 2 \mathrm{~m}}$. Further necropsyz findings are described below. In three patients with, and seven without, clinical signs there was radiolo- $\vec{\bullet}$ gical evidence of degenerative disc or facet joint ${ }_{0}^{\circ}$ disease, and none had evidence of ankylosing spondylitis. Two of these patients had 'destructive' disc lesions with loss of adjacent end plate, which resembled discitis. These occurred at T4/5, L3/4, and $L 4 / 5$ in one, and at $L 4 / 5$ in the other.

\section{Carpal tunnel syndrome}

CTS was diagnosed in seven patients, of whom six had undergone dialysis for over 10 years (Table 1): several had had repeated operations for carpaltunnel decompression. All seven patients with $\mathrm{CTS}$ had large or medium joint arthropathy, which was:associated with flexor tenosynovitis in two and smallB. joint synovitis in one. All had bone cysts.

\section{Bone cysts}

Bone cysts were seen with increasing frequency with? duration of dialysis, and $50 \%$ of patients in group on were affected (Table 4). These were usually in the

Table 5 Distribution of bone cysts (number of patients affected)

\begin{tabular}{|c|c|}
\hline Affected bones & Number of patiento \\
\hline Carpi & 12 \\
\hline Tibia & 1 \\
\hline Femur (head or neck) & 4 \\
\hline Humerus (head) & 1 \\
\hline Radius (distal) & 3 \\
\hline Navicular & 1 \\
\hline Phalanges & 4 \\
\hline Total number of affected patients & 21 \\
\hline
\end{tabular}


carpi (Table 5) (Fig. 1a), but long bones were also involved; one cyst affecting the tibial plateau required curettage and bone grafting to prevent fracture (Fig. 1b). Serial radiographs of a cyst in the femoral head were also obtained (Fig. 1c). In another, a large subchondral cyst in the head of the third proximal phalanx was associated with degenerative change in the adjacent joint. As noted above, there was a close association between the presence of bone cysts and CTS.

\section{Renal osteodystrophy}

Twenty nine patients had active hyperparathyroid-

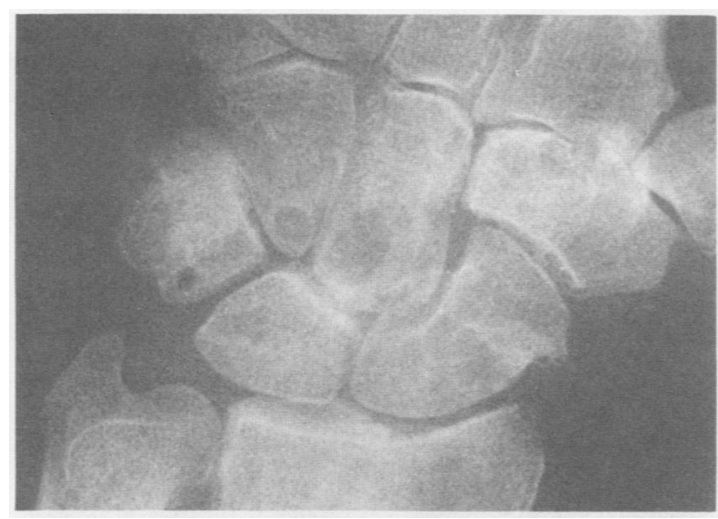

Fig. 1a

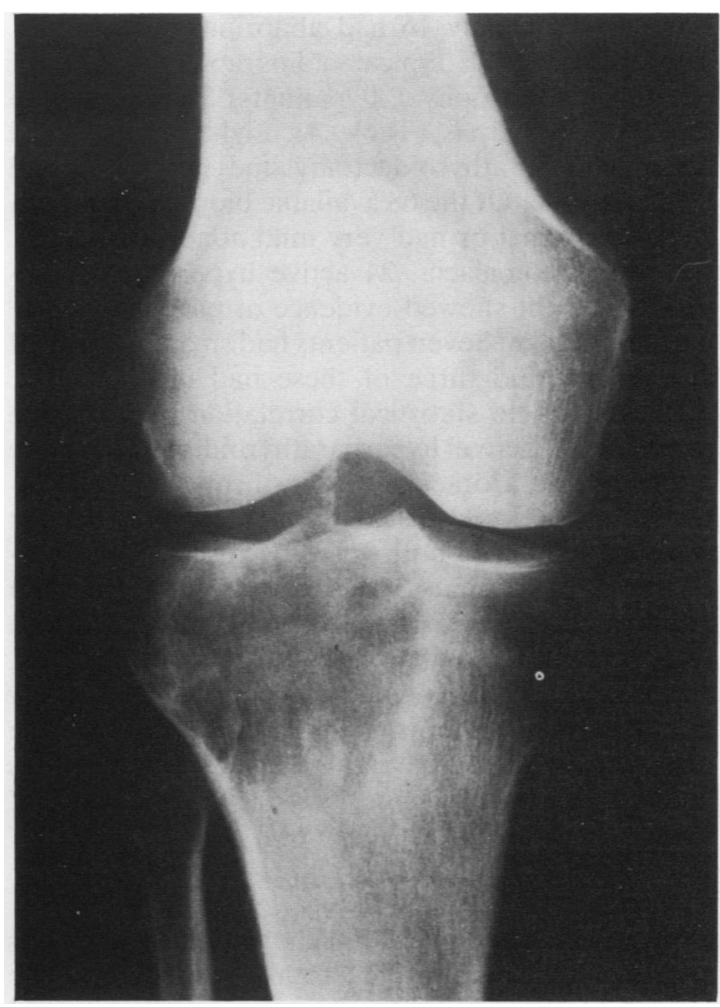

Fig. 1b
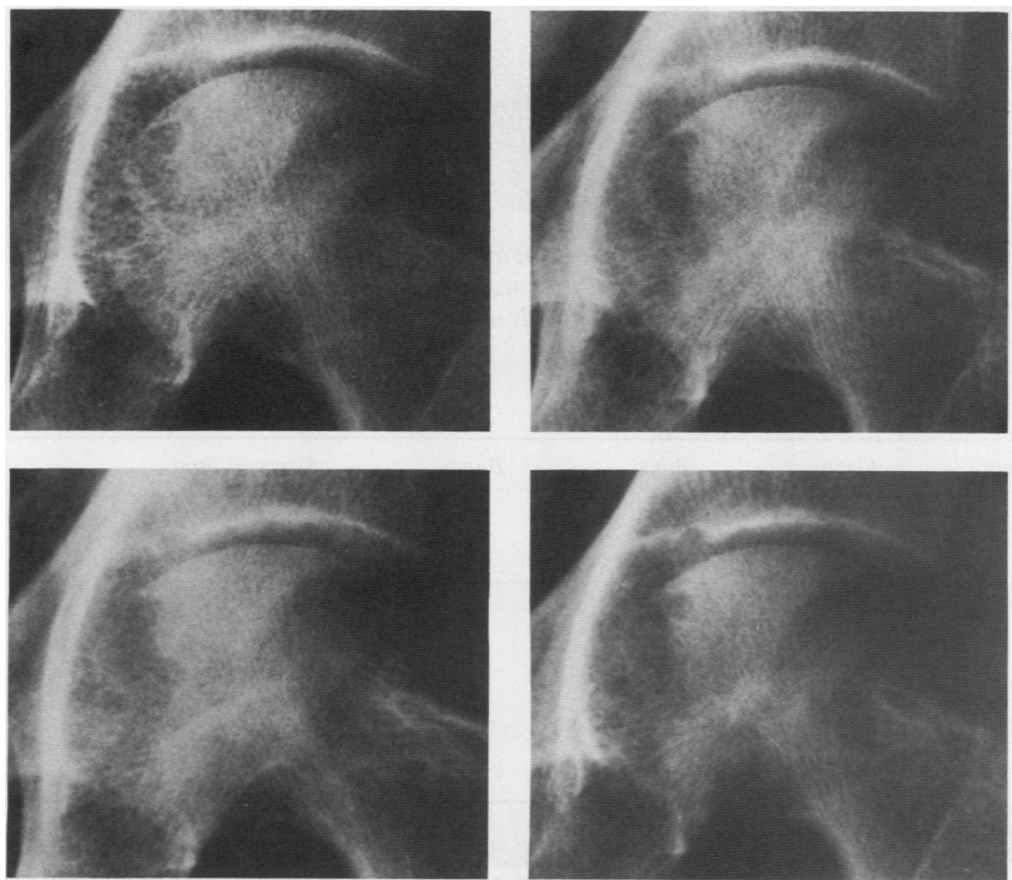

Fig. 1 Radiographs showing bone cysts in (a) carpi and (b) the tibial plateau of $a 78$ year old woman who had been dialysed for 10 years; there is no loss of articular cartilage overlying the tibial cyst. (c) Serial radiographs showing progression of $a$ destructive cyst in the femoral head of a 59 year old man who had received chronic haemodialysis for nine years-from top leftclockwise, 1983, 1984, 1985, 1987. Although articular cartilage overlying the cyst appears to be destroyed, it is preserved in the immediately adjacent superior aspect of the joint.

Fig. 1c 
ism, of whom only 16 had abnormal radiographs. The prevalence of typical radiographic changes of renal osteodystrophy (30 patients) increased with duration of dialysis (Table 4); eight of these had undergone parathyroidectomy and no longer had active disease. Of the 68 available biopsy specimens, 25 were normal or had very mild abnormalities, 11 showed osteomalacia, 24 active hyperparathyroidism, and eight showed evidence of previous hyperparathyroidism. Seven patients had small deposits of aluminium, and three of these had osteomalacia.

There was no statistical correlation between the presence of active hyperparathyroidism and bone cysts, erosive azotaemic osteoarthropathy, osteoarthritis or loss of articular cartilage in large or medium joints, or both, or erosive nodal osteoarthritis: 9/21 patients with bone cysts, 3/14 with erosive azotaemic osteoarthropathy, 12/30 with large or medium joint osteoarthritis or cartilage loss, and $8 / 14$ with erosive nodal osteoarthritis respectively had hyperparathyroidism $\left(\chi^{2}\right.$ test; $\left.p>0 \cdot 1\right)$. Both the patients with destructive intervertebral disc lesions had rugger jersey spines, and one had 'active' hyperparathyroidism.

\section{H IS TOLOGY}

One or more histological or synovial fluid specimens were available in life from a total of 15 patients. The indications for obtaining these were carpal tunnel release (seven patients), excision of bone cyst (one), and excision of iliopsoas bursa (one). Synovial fluid aspiration was performed in three of these patients and in a further seven patients with chronic large joint synovitis. Necropsy was performed on six patients, including two of the above 15 patients. Tissues in which $\mathrm{AM}_{\beta 2 \mathrm{~m}}$ deposition was identified by Congo red staining and by immunoperoxidase for $\beta_{2}$ microglobulin included carpal tunnel structures, synovium, and bone (Table 6).
Histology and necropsy results

In six of the seven patients with CTS $\mathrm{AM}_{\beta 2 \mathrm{~m}}$ was present in various carpal tunnel structures, including the flexor retinaculum, flexor tendon, and sheath? In the seventh patient dense fibrous tissue was seen in the retinaculum.

Electron microscopy studies on material from bone cysts and synovium demonstrated curvilinean fibrils (Fig. 2).

Necropsy material was available from six patients One patient, who had received dialysis for 14 years $\vec{\omega}$ had severe dialysis associated arthropathy with bone cysts, recurrent CTS, synovitis of wrists and knees $\frac{\bar{\alpha}}{2}$ restriction of shoulders, wrists, hips, and spine, ands rotator cuff attrition. As mentioned above ir apophyseal joint swelling and disc degeneration hads caused lumbar nerve root compression. At nec 6

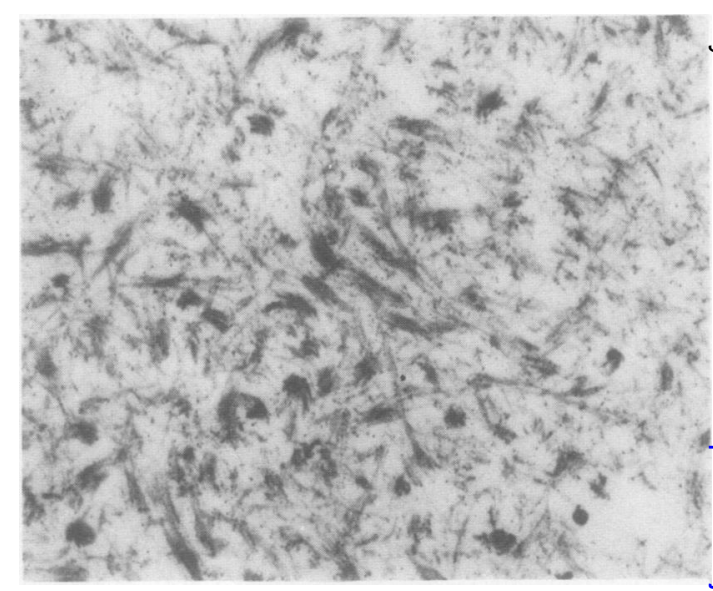

Fig. 2 Electron microscopy of amyloid identified by Congo red staining in the synovium of a knee. Short curvilinear fibrils of amyloid are seen.

Table 6 Sites of $A M_{\beta 2 m}{ }^{*}$ deposition

\begin{tabular}{|c|c|c|c|c|c|c|c|}
\hline \multirow{2}{*}{$\begin{array}{l}C H D^{*} \\
\text { duration } \\
\text { (years) }\end{array}$} & \multirow{2}{*}{$\begin{array}{l}\text { Carpal } \\
\text { tunnel }\end{array}$} & \multirow[t]{2}{*}{ Synovium } & \multirow{2}{*}{$\begin{array}{l}\text { Flexor } \\
\text { tendon }\end{array}$} & \multirow{2}{*}{$\begin{array}{l}\text { Bone } \\
\text { cyst }\end{array}$} & \multirow[t]{2}{*}{ Bursa } & \multicolumn{2}{|c|}{ Synovial fluid } \\
\hline & & & & & & $\begin{array}{l}\beta_{2} \text { Micro- } \\
\text { globulin }\end{array}$ & Congo red \\
\hline 12 & + & & & & & & $\frac{2}{2}$ \\
\hline $\begin{array}{l}10 \\
10\end{array}$ & $\begin{array}{l}+ \\
+\end{array}$ & & & Tibia & & $t$ & Strong \\
\hline 15 & $\begin{array}{l}+ \\
+\end{array}$ & & + & & & $\begin{array}{l}+ \\
+\end{array}$ & $\begin{array}{l}\text { Strong } \\
\text { Weak }\end{array}$ \\
\hline 14 & + & $\mathbf{N}+$ & + & $\mathrm{N}$, carpi & & & \\
\hline 6 & + & $\mathbf{N} \ddagger$ & $\mathbf{N}+$ & & & + & Negative \\
\hline 10 & & & & & $\S+$ & & -5 \\
\hline
\end{tabular}

${ }^{*} \mathrm{AM}_{\mathrm{\beta 2m}}=\boldsymbol{\beta}_{2}$ microglobulin related amyloid; $\mathrm{CHD}=$ chronic haemodialysis.

Only tissue sites in which deposits of $A M_{\beta 2 m}$ were identified are indicated. $+=A M_{\beta 2 m}$ present; $N=$ necropsy findings; $\dagger=$ shoulder $\sigma$ knee, hip, and lumbar apophyseal joints; $\ddagger=$ shoulder and knee; $\S=$ iliopsoas bursa excised seven years previously: this patient had nœ other features to suggest amyloidosis. 
ropsy, deposits of $\mathrm{AM}_{\beta 2 \mathrm{~m}}$ were found in the synovium of shoulder, hip, knee, and carpal tunnel structures, including flexor tendon and retinaculum, but not median nerve. In the spine it was present in the synovium of lumbar apophyseal joints and in a degenerating lumbar disc but not in two adjacent, macroscopically normal, lumbar intervertebral discs. In general the amyloid was arranged in nodules (Fig. 3), which were not perivascular. Mononuclear cells, mainly lymphocytes, were numerous in the knee and shoulder but not the hip. There was also a moderate degree of synovial hyperplasia. Special stains for tissue deposits of iron showed moderate increases in synovial iron stores in the knees, a little in the shoulder, and none in other structures infiltrated by $\mathrm{AM}_{\beta 2 \mathrm{~m}}$, including hips, lumbar apophyseal joints, intervertebral disc or synovium of carpal tunnel, and flexor tendons. Synovial iron deposits were associated with a mononuclear infiltrate. No amyloid was identified in any other major organ.

A second patient, who had been dialysed for six years, had synovitis and restriction of shoulders and mild, clinically insignificant symptoms of CTS. At necropsy, six months after clinical review, $\mathrm{AM}_{32 \mathrm{~m}}$ was identified in the flexor retinaculum, median nerve, and synovium of shoulder and knee. No iron deposits or mononuclear cells were seen in any of these sites.
Necropsy was performed on three other subjects. Two had received haemodialysis for two years and one had had peritoneal dialysis for five months followed by two renal grafts lasting eight months before death. No amyloid was found in synovium from the carpal tunnel or adjacent structures, shoulders, hips, or knees. There had been no signs or symptoms of arthropathy or CTS during life.

Limited necropsy material was obtained from the finger of a sixth patient who had died two years after commencing CHD. The only articular abnormality in life was erosive nodal osteoarthritis affecting the distal interphalangeal joints. No amyloid deposits were found in the synovium or periarticular structures of an affected distal interphalangeal joint.

\section{Synovial fluid}

Synovial fluid obtained from the knees or shoulders of patients with chronic joint swelling was usually of high viscosity with small numbers of mononuclear cells. In three patients with histologically proved $\mathrm{AM}_{\beta 2 \mathrm{~m}}$ in synovial or carpal tunnel structures the synovial fluid sediment was positive on immunoperoxidase staining for $\beta_{2}$ microglobulin (Table 6). In a further seven patients synovial fluid deposits also gave positive staining with immunoperoxidase. The staining pattern was usually fibrillar, but occasional amorphous clumps of $\mathrm{AM}_{32 \mathrm{~m}}$ were seen in $6 / 10$ patients. Only one was strongly positive with

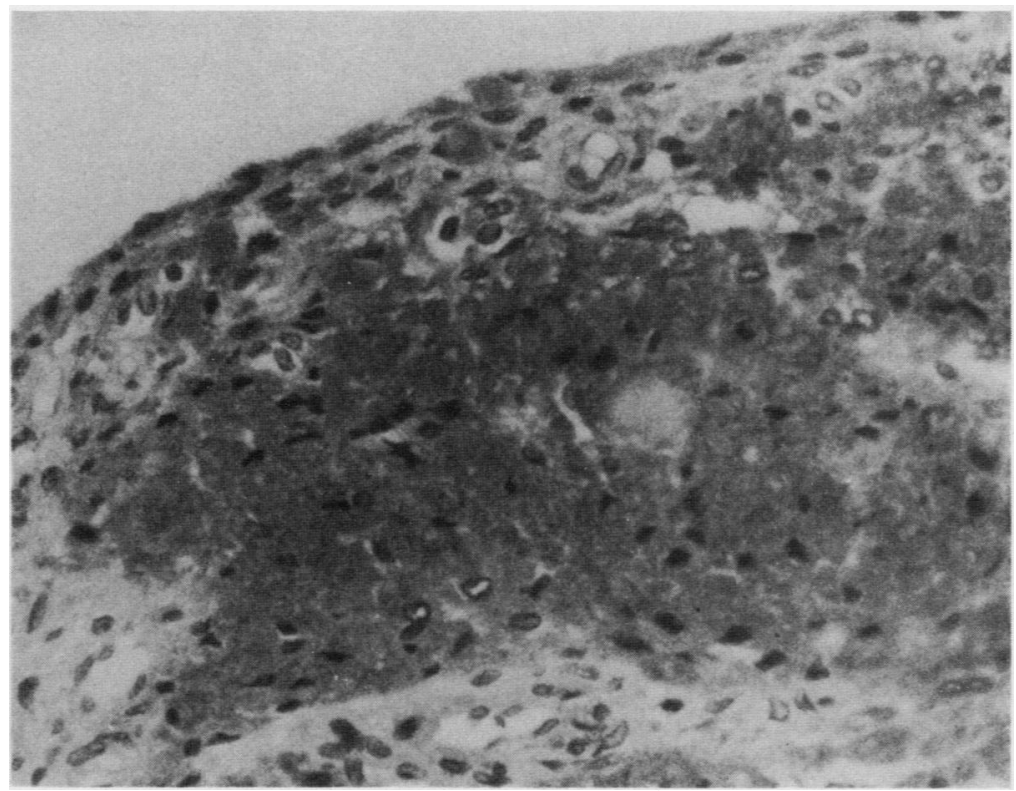

Fig. 3 Nodular synovial deposit of $\beta_{2}$ microglobulin related amyloid demonstrated by immunoperoxidase. 
Congo red, however, three were weakly positive, and five were negative. Control studies using synovial fluid from patients with rheumatoid arthritis gave negative results using both techniques.

\section{B I OCH EM IS T R Y}

\section{Serum $\beta_{2}$ microglobulin}

Serum $\beta_{2}$ microglobulin concentrations before dialysis, which were available from $91 / 95$ patients, were markedly raised (normal range $1-3 \mathrm{mg} / \mathrm{l}$ ) and remained approximately constant with increasing duration of dialysis (Fig. 4). $\beta_{2}$ Microglobulin concentrations rose on average by about $4 \mathrm{mg} / \mathrm{l}$ during dialysis (data not shown), returning to predialysis concentrations between each session.

Within each cohort patients with chronic synovitis, CTS, or bone cysts did not have higher concentrations of serum $\beta_{2}$ microglobulin than those without these features (Table 7).

\section{Serum ferritin}

Serum ferritin concentrations were measured as an index of total iron stores and were available for 92/95 patients. Patients with large joint chronic synovitis had a wide scatter of serum ferritin concentrations, which clearly did not differ from

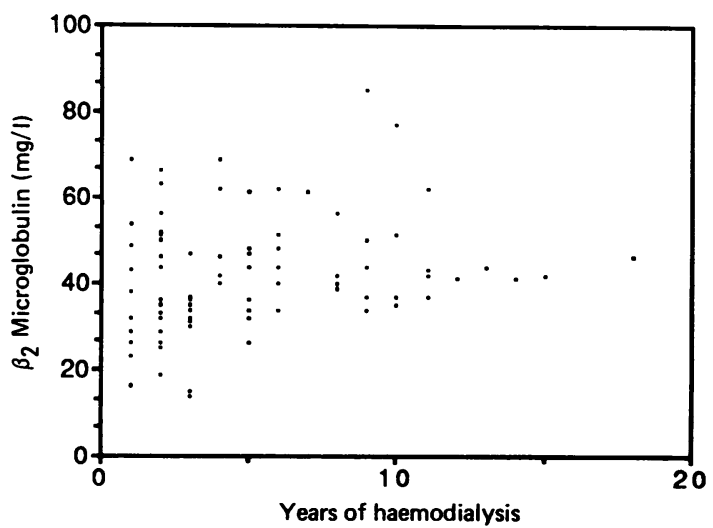

Fig. 4 Relation between serum $\beta_{2}$ microglobulin and duration of dialysis. those without synovitis (Fig. 5). Of the six patientș with radiological evidence of large joint cartilage erosion without osteoarthritis, only one had mod $\stackrel{\text { ? }}{9}$ estly raised serum ferritin $(340 \mu \mathrm{g} / \mathrm{l})$.

The relation between increased serum ferritin and

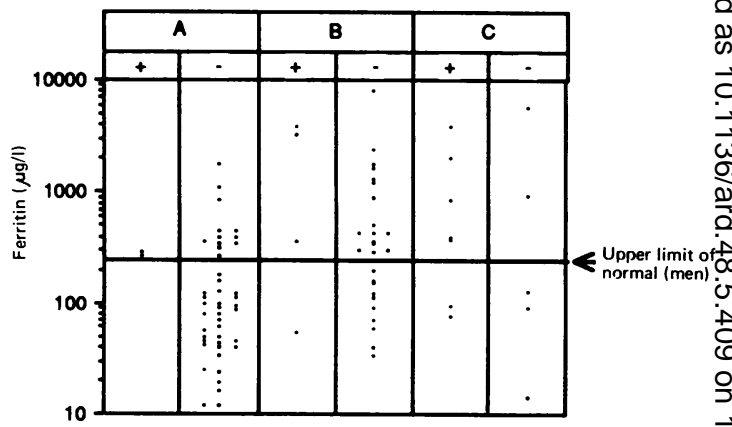

Fig. 5 Serum ferritin concentrations in patients undergoing chronic haemodialysis with (+) or without (-) chronic large joint synovitis, in each cohort $A, B$, and $C$. Many patients with substantially increased serum ferritin do not have synovitis. There was no significant difference in the proportion of patients with increased serum ferritin among those with synovitis compared with those without ( $\chi^{2}$ test; $p>0.5)$.

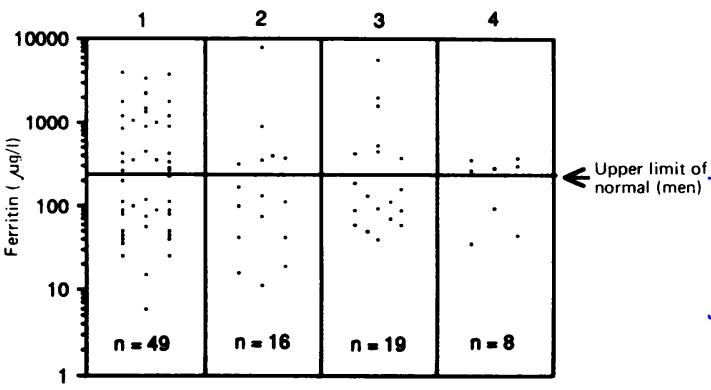

Fig 6 Distribution of serum ferritin in patients with or without osteoarthritis. (1) No osteoarthritis; (2) large joint osteoarthritis only; (3) small joint osteoarthritis only; and (4) small and large joint osteoarthritis. There was no significant difference in the proportion with serum ferritin $>250 \mu \mathrm{g} / \mathrm{l}$ in the group without osteoarthritis as compared with those with large joint osteoarthritis, small joint osteoarthritis, or both $\left(\chi^{2}\right.$ test; $\left.p>0 \cdot 1\right)$.

Table 7 Mean (SD) serum $\beta_{2}$ microglobulin concentrations

\begin{tabular}{|c|c|c|c|}
\hline & \multicolumn{3}{|c|}{ Serum $\beta_{2}$ microglobulin $(m g / l)$} \\
\hline & $\boldsymbol{A}$ & $B$ & $C$ \\
\hline \multicolumn{4}{|c|}{ Clinical signs } \\
\hline Absent & $39.6(13.5) \quad(n=42)$ & $46 \cdot 3(12 \cdot 3) \quad(n=21)$ & $61 \cdot 7(12 \cdot 7) \quad(n=4)$ \\
\hline Present & $40.3(12.9) \quad(n=7)$ & $42.5(9.9)(n=11)$ & $41 \cdot 3(4 \cdot 3) \quad(n=10)$ \\
\hline
\end{tabular}

Serum $\beta_{2}$ microglobulin concentrations in patients with or without clinical signs of synovial swelling, carpal tunnel syndrome, or bone cysts $O$ analysed according to duration of dialysis, which was as follows: $A=0-4.9$ years; $B=5-9.9$ years; $C=\geqslant 10$ years. 
the development of osteoarthritis in large joints or small joints of the hands was also examined, but no correlation was found (Fig. 6). Many patients had substantially raised serum ferritin concentrations $(>1000 \mu \mathrm{g} / \mathrm{l})$ without any evidence of osteoarthritis, synovitis, or other arthropathy. Similarly, there was no correlation between raised ferritin concentraions and either CTS or bone cysts.

\section{Discussion}

Despite extensive reporting the epidemiology and aetiology of rheumatic disease in patients receiving CHD remain poorly defined. ${ }^{27}$ In this study of 95 patients receiving CHD the prevalence, clinical and radiological features of rheumatic disease, and its relation to $\mathrm{AM}_{\beta 2 \mathrm{~m}}$ deposition, hyperparathyroidism, duration of dialysis, and various biochemical parameters were examined.

A striking finding was the high and increasing prevalence of symptoms and signs of joint disease with increasing duration of dialysis. The overall clinical picture was of a chronic arthropathy with synovitis or restriction, or both, affecting predominantly shoulders, knees, hips, and, to a lesser extent, elbows, wrists, and spine. Other important associations of this arthropathy included CTS, bone cysts, and, less frequently, flexor tenosynovitis of fingers. In a few patients haemarthrosis was seen. This clinical picture is consistent with previous reports, ${ }^{3} 10-12233$ though hip involvement was more frequent than had been appreciated. Histological studies in life and at necropsy confirmed that deposition of $\mathrm{AM}_{\beta 2 \mathrm{~m}}$ is a major cause of CTS and large joint swelling, and that $\mathrm{AM}_{\beta 2 \mathrm{~m}}$ is a major constituent of bone cysts. It may also be responsible for the high prevalence of hip restriction. The deposition of $\mathrm{AM}_{\beta 2 \mathrm{~m}}$ is clearly related to duration of dialysis and it was not found at necropsy in the synovium and carpal tunnel of three patients who had received dialysis for two years or less. Deposition of $\mathrm{AM}_{\beta 2 \mathrm{~m}}$ may be accelerated at sites of inflammation as indicated by its presence in an iliopsoas bursa after three years of CHD. Seven years later this patient had no other evidence of amyloidosis.

Chronic swelling and restriction of large joints was not always accompanied by significant radiological evidence of joint damage. Of those with clinical abnormalities of knees, shoulders, and hips, $5 / 12,5 / 16$, and $10 / 17$ patients respectively had no significant radiological abnormality. The main radiographic abnormalities identified included rotator cuff destruction, osteoarthritis with loss of cartilage, and, in a few, loss of articular cartilage without osteoarthritis.

The histological and synovial fluid examinations which were performed, taken in conjunction with other reported synovial histology, suggest that the synovial swelling in most patients with dialysis related arthropathy is due to massive infiltration by $\mathrm{AM}_{\beta 2 \mathrm{~m}}$. In the absence of synovial iron deposits no cellular infiltrate was seen. It cannot be assumed that synovial $\mathrm{AM}_{\beta 2 \mathrm{~m}}$ is necessarily a cause of joint damage as about half of the patients with clinical or histological evidence of synovial $\mathrm{AM}_{\beta 2 \mathrm{~m}}$ had no radiological abnormalities. Furthermore, the prevalence of joint lesions, such as cartilage erosion and severe rotator cuff disease, which have been attributed to $\mathrm{AM}_{\beta 2 \mathrm{~m}}$, were a function of age rather than duration of dialysis. Thus synovial deposition of $\mathrm{AM}_{\beta 2 \mathrm{~m}}$ in damaged joints may simply be a secondary phenomenon, which is more likely to occur in diseased or inflamed tissue, rather than a primary aetiological event.

On the other hand, subchondral deposits of $\mathrm{AM}_{\beta 2 \mathrm{~m}}$ may be directly responsible for joint damage. $A_{\beta 2 m}$ deposits in subchondral bone have been reported to precede articular space narrowing by some years ${ }^{21}$; destruction of articular cartilage was observed in one of three patients with a subchondral cyst in a large joint (Fig. 1c). Damage in this joint was localised to the immediate area over the deposit while the adjacent joint space appeared to be preserved. Degenerative changes were also noted in a metacarpophalangeal joint adjacent to a large phalangeal cyst. The mechanism of destruction is not certain but may simply be the mechanical effects of an enlarging deposit.

The possible role of hyperparathyroidism in causing large or medium joint damage was also examined, but no correlation was found between active hyperparathyroidism and either large or medium joint osteoarthritis, rotator cuff disease, or synovitis. Ligamentous laxity ${ }^{34}$ and collapse of subchondral bone, leading to destructive joint lesions and secondary osteoarthritis, can occur, however, in patients with primary or secondary hyperparathyroidism. ${ }^{35}$ Thus previous episodes of hyperparathyroidism may also be important in the aetiology of peripheral joint attrition.

Synovial iron deposition secondary to iron overload or recurrent haemarthrosis may also be an important factor in the pathogenesis of joint damage. $^{36}$ Although there was no association between total iron stores, as measured by serum ferritin concentrations, and arthropathy, in one necropsy study a relation was noted between the amount of synovial iron, the number of infiltrating mononuclear cells, and the extent of joint damage. Caution is needed in interpreting these data as the iron and cellular infiltrate may simply be secondary to recurrent bleeding in a damaged joint.

Further prospective studies are needed to deter- 
mine more precisely the relative contributions of synovial or subchondral deposits of $\mathrm{AM}_{\beta 2 \mathrm{~m}}$, hyperparathyroidism, synovial iron deposits, and age to the pathogenesis of large and medium joint arthritis in patients receiving CHD.

Symptoms of pain and stiffness in the hands were frequent and increased markedly with increasing duration of dialysis. In four patients this was attributed clinically to nodular tenosynovitis, which in two was due to $\mathrm{AM}_{\beta 2 \mathrm{~m}}$ deposition within the flexor tendons. Osteoarthritis was also responsible for symptoms in some patients, but in this series erosive osteoarthritis was correlated with age rather than duration of dialysis. In two patients it occurred at an unusually young age, suggesting that factors associated with renal failure may contribute. No $\mathrm{AM}_{\beta 2 \mathrm{~m}}$ was identified in an affected distal interphalangeal joint of a patient with erosive osteoarthritis at necropsy, confirming that amyloid plays no part in this condition. Most of the 14 patients with erosive azotaemic osteoarthropathy had no small joint symptoms, and the condition did not correlate with evidence of active hyperparathyroidism. This is concordant with a study by Sundaram $e a^{37}$ but not with that by Rubin et al. ${ }^{38}$ Overall, the increasing frequency of small joint pain and stiffness with duration of dialysis was not satisfactorily accounted for by clinical signs of synovitis or deformity, or by radiographic evidence of joint space narrowing, osteoarthritis, or erosive azotaemic osteoarthropathy.

Pain, stiffness, and restriction of the spine were relatively common, and in a few symptoms were attributable to mild degenerative disc or facet joint disease. Two patients had destructive disc lesions with loss of adjacent end plate. The appearances were similar to the destructive spondyloarthropathy reported recently, which has been attributed in turn to either apatite ${ }^{39}$ or $\mathrm{AM}_{\beta 2 \mathrm{~m}}$ deposition. ${ }^{25}$ One of these two patients had extensive $\mathrm{AM}_{\beta 2 \mathrm{~m}}$ deposition in synovium, including apophyseal joints, and bone; $\mathrm{AM}_{\beta 2 \mathrm{~m}}$ also was found in the degenerate lumbar vertebral disc but not in adjacent macroscopically normal lumbar discs. This patient had previously had a parathyroidectomy and had a rugger jersey spine. Similar destructive spondylotic lesions have been described in primary and secondary hyperparathyroidism and appear to be caused by collapse of juxta-articular bone. ${ }^{35}$ This may have been the mechanism in our two patients and in the others in whom this has been reported. ${ }^{25} 39$ As premorbid deposits of $\mathrm{AM}_{\beta 2 \mathrm{~m}}$ were absent from other macroscopically normal discs in the patient described above $\mathrm{AM}_{\beta 2 \mathrm{~m}}$ deposition is probably a consequence rather than a cause of disc degeneration. ${ }^{27}$

$\mathrm{AM}_{\beta 2 \mathrm{~m}}$ was identified by immunoperoxidase in synovial fluids from several patients with suspectects or histologically proved synovial $\mathrm{AM}_{\beta 2 \mathrm{~m}}$. Contro studies on synovial fluid from patients with active? rheumatoid arthritis were negative. Synovial flui $\$$ from a patient with acute exacerbation of ankylosing spondylitis, who had recently started CHD treat? ment and is therefore not included in the survey? also gave negative results for $\mathrm{AM}_{\beta 2 \mathrm{~m}}$. Attempts t\& verify that positive immunochemical results corre $\vec{P}$ lated with the presence of Congophilic materiaf were largely unsuccessful. The failure to identif $\vec{\omega}$ $\mathrm{AM}_{\beta 2 \mathrm{~m}}$ using Congo red may be due to the lack of sensitivity of this technique compared with im munochemical methods. Recently we treated synovial fluid sample from a newly diagnoseद्ध patient with hyaluronidase in an attempt to ensures more complete recovery of fibrils during centrifuga tion. This specimen gave positive results with bot? immunoperoxidase and Congo red techniques. It seems likely that failure to obtain Congo ref staining in sediments which are immunoreactive for $\beta_{2}$ microglobulin is due to false positive results witho the immunochemical technique; for example, sole uble $\beta_{2}$ microglobulin may simply have precipitated as an amorphous deposit. This technique ${ }^{24}$ require further evaluation before it can be accepted as diagnostically useful.

We also examined the relation between serum microglobulin and the $\mathrm{AM}_{\beta 2 \mathrm{~m}}$ related syndrome Contrary to some reports, ${ }^{40}$ but in agreement wit others, ${ }^{41}$ we found little or no rise in serum $\beta_{3}^{3}$ microglobulin concentrations with increasing durat tion of dialysis. Also as reported previously, we found a transient rise in serum $\beta_{2}$ microglobulif during each dialysis ${ }^{41}{ }^{42}$ and no correlation betwee the development of the $\mathrm{AM}_{\beta 2 \mathrm{~m}}$ related syndrome. and serum $\beta_{2}$ microglobulin concentrations. ${ }^{41}$ Thi final total body pool of $\beta_{2}$ microglobulin-that is soluble and insoluble, is presumably a more imporo tant factor than serum $\beta_{2}$ microglobulin in determin? ing the development of the $\mathrm{AM}_{\beta 2 \mathrm{~m}}$ related syre drome.

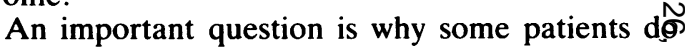
not develop dialysis related arthropathy and itto associated features even after many years of $\mathrm{CHD}$ Five of the 14 patients in cohort $C$ had no features - that is, CTS, bone cysts, or synovitis, t8 suggest that they had the $\mathrm{AM}_{\beta 2 \mathrm{~m}}$ related syndromeThe mean (SD) age of these five patients (38. (4.76) years) was significantly less than that of the other nine $(59.7(10.71)$ years $)(\mathrm{p}<0.01$; Student's unpaired $t$ test). This trend was also apparent i cohorts A and B but did not reach statisticall significance. Thus age may be an important factof determining predisposition to the development of amyloidosis. 
In summary, at least three clinically distinct subgroups of patients with arthropathy were identified-patients with the $\mathrm{AM}_{\beta 2 \mathrm{~m}}$ related syndrome of synovial swelling, tenosynovitis, CTS, and bone cysts; a second group with erosive azotaemic osteoarthropathy; and a third group with degenerative joint disease affecting small, large, or axial joints.

A number of important conclusions may be drawn concerning the aetiology of these conditions. Firstly, $\mathrm{AM}_{\beta 2 \mathrm{~m}}$ deposition increases with duration of dialysis and causes synovial swelling, nodular tenosynovitis, bone cysts, and CTS; in patients receiving long term (>10 years) $\mathrm{CHD}$, however, the risk of developing $\mathrm{AM}_{\beta 2 \mathrm{~m}}$ was related to age. Deposition of $\mathrm{AM}_{\beta 2 \mathrm{~m}}$ in subchondral bone, but not synovium, causes joint damage, and $\mathrm{AM}_{\mathrm{B2m}}$ may be more prone to deposition in synovium already damaged by other pathological processes. In the absence of synovial iron deposition synovial $\mathrm{AM}_{\beta 2 \mathrm{~m}}$ is not associated with an inflammatory infiltrate. Although the data are inconclusive, hyperparathyroidism may have a role in the pathogenesis of destructive spondyloarthropathy and perhaps of the degenerative disease of peripheral joints in some patients. The failure to confirm a correlation between hyperparathyroidism and erosive azotaemic osteoarthropathy may be due to difficulties in the accurate ascertainment of hyperparathyroidism in patients receiving CHD. No correlation was found between serum ferritin and arthritis, and the significance of synovial iron deposition is unclear.

As some of the features of dialysis related arthropathy may be ameliorated by alterations in dialysis technique or other therapeutic intervention further well designed prospective studies are urgently needed to clarify the pathogenetic mechanisms responsible for joint damage in these patients.

We thank Professor Barry Vernon-Roberts for reporting results of bone histology, Mr David Gove for performing electron microscopy studies, and Dr S C Milazzo for helpful criticism of this manuscript.

\section{References}

1 Massry S G, Bluestone R, Klinenberg J R, Coburn J W. Abnormalities of the musculoskeletal system in haemodialysis patients. Semin Arthritis Rheum 1975; 4: 321-49.

2 Brown E A, Gower P E. Joint problems in maintenance haemodialysis. Clin Nephrol 1982; 18: 247-50.

3 Brown E A, Arnold I R, Gower P E. Dialysis arthropathy: complication of long term treatment with haemodialysis. $\mathrm{Br}$ Med J 1986; 292: 163-6.

4 Warren D J, Otieno L S. Carpal tunnel syndrome in patients on intermittent haemodialysis. Postgrad Med J 1975; 51: 450-2.

5 Jain V K, Cestero R V M, Baum J. Carpal tunnel syndrome in patients undergoing maintenance haemodialysis. JAMA 1975; 242: 2868 .
6 Schwarz A, Keller F, Seyfert S, Poll W, Molzahn M, Distler A. Carpal tunnel syndrome: a major complication in long-term haemodialysis patients. Clin Nephrol 1984; 22: 133-7.

7 Spertini F, Wauters J P, Poulenas I. Carpal tunnel syndrome: a frequent invaliding long term complication of chronic haemodialysis. Clin Nephrol 1984; 21: 98-101.

8 Assenat H, Calemard E, Charra B, Laurent G, Terrat J C, Vanel T. Hémodialyse, syndrome du canal carpien et substance amyloide [Abstract]. La Nouvelle Presse Medicale 1980; 9: 1715.

9 Goldstein S, Winston E, Chung T J, Chopra S, Pariser K. Chronic arthropathy in long term haemodialysis. Am J Med 1985; 78: 82-6.

10 Fenves A Z, Emmett M, White M G, Greenway G, Michaels D B. Carpal tunnel syndrome with cystic bone lesions secondary to amyloidosis in chronic haemodialysis patients. Am J Kidney Dis 1986; 7: 130-4.

11 Bardin T, Kuntz D, Zingraff J, Voisin M-C, Zelmar A, Lansaman J. Synovial amyloidosis in patients undergoing long term haemodialysis. Arthritis Rheum 1985; 28: 1052-8.

12 Munoz-Gomez J, Bergada-Barado E, Gomez-Perez R, et al. Amyloid arthropathy in patients undergoing periodical haemodialysis for chronic renal failure: a new complication. Ann Rheum Dis 1985; 44: 729-33.

13 Huaux J P, Noel H, Malghem J, Maldague B, Devogelaer J P, Nagant de Deuxchaisnes C. Erosive azotemic osteoarthropathy: possible role of amyloidosis, Arthritis Rheum 1985; 28: 1075-6.

14 Charra B, Calemard E, Uzan M, Terrat J C, Vanel T, Laurent G. Carpal tunnel syndrome, shoulder pain and amyloid deposits in long term haemodialysis patients. Kidney Int 1984; 26: 549 .

15 Geyjo F, Yamada T, Odani S, et al. A new form of amyloid protein associated with chronic hemodialysis was identified as B2-microglobulin. Biochem Biophys Res Commun 1985; 129: 701-6.

16 Connors L H, Shirama T, Skinner M, Fenves A, Cohen A S. In vitro formation of amyloid fibrils from intact $\beta 2$-microglobulin. Biochem Biophys Res Commun 1985; 131: 1063-6.

17 Geyjo F, Odani S, Yamada T, et al. B2-Microglobulin: a new form of amyloid protein associated with chronic hemodialysis. Kidney Int. 1986; 30: 385-90.

18 Gorevic P D, Casey T T. Stone W J, DiRaimondo C R, Prelli F C, Frangione B. Beta-2 microglobulin is an amyloidogenic protein in man. $J$ Clin Invest 1985; 76: 2425-9.

19 Casey T T, Stone W J, DiRaimondo C R, Page D L, Gorevic P D. Dialysis-related amyloid is amyloid of beta-2microglobulin $\left(\mathrm{AM}_{\beta 2 \mathrm{M}}\right)$ origin. Arthritis Rheum 1986; 29: 1170.

20 McClure J, Bartley C J, Ackrill P. Carpal tunnel syndrome caused by amyloid containing $\beta_{2}$ microglobulin: a new amyloid and a complication of long term haemodialysis. Ann Rheum Dis 1986; 45: 1007-11.

21 Bardin $\mathrm{T}$, Zingraff $\mathrm{J}$, Shirahama $\mathrm{T}$, et al. Hemodialysisassociated amyloidosis and beta- 2 microglobulin. Clinical and immunohistochemical study. Am J Med 1987; 83: 419-24.

22 Shirahama T, Skinner M, Cohen A S, et al. Histochemical and immunohistochemical characterisation of amyloid associated with chronic hemodialysis as $\beta 2$-microglobulin. Lab Invest 1985; 53: 705-9.

23 Muñoz-Gómez J, Gómez-Pérez R, Llopart-Buisán E, SoléArqués $M$. Clinical picture of the amyloid arthropathy in patients with chronic renal failure maintained on haemodialysis using cellulose membranes. Ann Rheum Dis 1987; 46: 573-9.

24 Muñoz-Gómez J, Gómez-Pérez R, Solé-Arques M, LlopartBuisán E. Synovial fluid examination for the diagnosis of synovial amyloidosis in patients with chronic renal failure undergoing haemodialysis. Ann Rheum Dis 1987; 46: 324-6.

25 Sebert J-L, Fardellone P, Marie A, et al. Destructive spondylarthropathy in hemodialysed patients: possible role of amyloidosis. Arthritis Rheum 1986; 29: 301-3. 
420 Hurst, van den Berg, Disney, Alcock, Albertyn, Green, Pascoe

26 Noel L H, Zingraff J, Bardin T. Atienza C, Kuntz D. Drueke T. Tissue distribution of dialysis amyloidosis. Clin Nephrol 1987; 27: 175-8.

27 Bardin T, Zingraff J, Kuntz D. Drueke T. Dialysis-related amyloidosis. Nephrology, Dialysis and Transplantation 1986; 1: 151-4.

28 Hickling P, Wilkins M. Newman G R. et al. A study of amyloid arthropathy in multiple myeloma. $Q J$ Med $1981 ; 200$ : $417-33$.

29 Ladefoged C. Amyloid in osteoarthritic hip joints: deposits in relation to chondromatosis, pyrophosphate and inflammatory cell infiltrate in the synovial membrane and fibrous capsule. Ann Rheum Dis 1983; 42: 659-64.

30 Huaux J P, Noël H, Bastien P, et al. Amylose articulaire. fracture du col fémoral, et hémodialyse périodique chronique. Rev Rhum Mal Osteoartic 1985; 52: 179-82.

31 DiRaimondo C R, Casey T T, DiRaimondo C V, Stone W J. Pathological fractures associated with idiopathic amyloidosis of bone in chronic hemodialysis patients. Nephron 1986; 43: 22-7.

32 Bardin T. Dialysis related amyloidosis. J Rheumatol 1987; 14: 647-8.

33 Hardouin P, Flipo R-M, Foissac-Gegoux P, et al. Current aspects of osteoarticular pathology in patients undergoing hemodialysis: study of 80 patients. Parts I and II. $J$ Rheumatol 1987; 14: 780-3, 784-7.

34 Resnick D, Niwayama G. Parathyroid disorders and renal osteodystrophy. In: Diagnosis of bone and joint disorders. Vote II. Philadelphia: Saunders, 1981: 1801-59.

35 Bywaters E G L, Dixon A St J. Scott J T. Joint lesions o hyperparathyroidism. Ann Rheum Dis 1963; 22: 171-87.

36 Cary N R, Sethi D, Brown E A, Erhardt C C, Woodrow D FO Gower P E. Dialysis arthropathy: amyloid or iron? $\mathrm{Br}$ Med $\underline{\underline{\underline{D}}}$ 1986; 293: 1392-4.

37 Sundaram M. Wolverson M K. Heiberg E. Grider R D. Erosive्D azotemic osteoarthropathy. AJR 1981: 136: 363-7.

38 Rubin L A, Fam A G. Rubenstein J. Campbell J. Saiphoo C ָొ Erosive azotemic osteoarthropathy. Arthritis Rheum 1984; 27:1086-94.

39 Kuntz D, Naveau B, Bardin T. Drueke T. Treves R, Dryll A Destructive spondylarthropathy in hemodialysed patients Arthritis Rheum 1984; 27: 369-75.

40 Blumberg A, Burgi W. Behaviour of $\beta 2$-microglobulin in patients with chronic renal failure undergoing hemodialysis hemodiafiltration and continuous ambulatory peritoneal dialysị (CAPD). Clin Nephrol 1987; 27: 245-9.

41 Geyjo F. Homma N. Suzuki Y, Arakawa M. Serum levels of $\beta 2$-microglobulin as a new form of amyloid protein in patient@ undergoing long term hemodialysis. $N$ Engl J Med 1986; 3140 $585-6$.

42 Karlsson F A, Wibell L, Evrin P E. $\beta 2$-Microglobulin in clinical medicine. Scand J Clin Lab Invest 1980; 40: 27-37. 